Feedback Trading and Intermittent Market Turbulence

Demosthenes N. Tambakis

October 2008

CWPE 0847 


\title{
Feedback Trading and Intermittent Market Turbulence
}

\author{
Demosthenes N. Tambakis* \\ Faculty of Economics \& Pembroke College \\ University of Cambridge
}

August 4, 2008

\begin{abstract}
This paper studies the potential for complex asset return dynamics in a high-frequency, non-fundamental feedback trading model. Price adjustment is driven by the time-varying price impact of net orderflow. In tranquil times feedback trading has no impact on the price level. Given feedback trading intensities, as asset liquidity declines the market progressively becomes stressed and turbulent. Returns and absolute returns persistence are found to display power-law features, and episodes of turbulence are intermittent.
\end{abstract}

Keywords: Feedback trading, Price impact, Financial stability, Intermittence, Power law.

JEL classification: G12, G14

*The author is grateful to ALBA Graduate Business School, Athens for its hospitality, to seminar participants at the Bank for International Settlements (BIS), Australasian Econometric Society Meetings 2006, Cambridge-Princeton Finance Seminar 2006, and Cantab Capital Partners, and to Andrew Filardo, Bill Janeway, Ewan Kirk, Steven Satchell, Jose Scheinkman, Nikola Tarashev, Christian Upper, and three anonymous referees for their valuable comments. The usual disclaimer applies. E-mail address: dnt22@cam.ac.uk. 


\section{Introduction}

Market liquidity can evaporate in turbulent trading conditions, a phenomenon referred to as a "liquidity black hole" by Taleb (1997) and Persaud (2003). Sharp drops in liquidity associated with discontinuous rises in price impact create market stress and undermine investor confidence. ${ }^{1}$ Negative sentiment can spread across financial markets, and what starts as an assetspecific crisis may end up having very costly systemic repercussions; see Borio (2000) and Cifuentes et al. (2004). In that regard, Morris and Shin (2004) show that net selling pressure can arise endogenously from the strategic interaction of long- and short-horizon traders. When the latter have privately-known liquidity constraints, these authors locate a unique trigger point at which a liquidity black hole emerges, and produce $\mathrm{V}$-shaped price reversals consistent with Campbell, Grossman and Wang (1993) and Pastor and Stambaugh (2003). Understanding the onset of such catastrophic events is important for financial practitioners and policymakers alike.

In this paper I study the potential for high-frequency market stress and/or turbulence in the absence of information asymmetries or fundamental news. Specifically, market participants' asset demand is generated by two feedback rules at high frequency. First, according to positive feedback, investors buy (sell) the risky asset if its return over the last trading interval was positive (negative). Such trend-following amplifies price fluctuations in either direction and can become self-reinforcing in models with boundedly rational traders and short horizons; see Abreu and Brunnermeier (2003) and Brunnermeier and Pedersen (2005).

\footnotetext{
${ }^{1}$ Such headline episodes include the 1987 stock market crash, the collapse of the U.S. dollar against the yen on October 7, 1998, distressed trading in certain fixed income markets during the LTCM crisis in the summer of 1998, and the recent liquidity crisis driven by the U.S. sub-prime mortgage market in August 2007.
} 
Second, following risk feedback, investors sell more (less) of the risky asset if its squared return in the last trading interval was high (low). Risk feedback trading always induces net selling pressure, and its absolute contribution to net orderflow rises (declines) during volatile (tranquil) periods. The information content of a larger absolute (square) return is that mean reversion to fundamentals-based price level-however defined-becomes more likely. In the presence of fundamental information, this may reflect Black's (1986) hypothesis that "the farther the price of a stock is from its [fundamental] value, the more aggressive the information traders become". In a continuous-time framework, Longstaff (2001) also shows that liquidity-constrained investors may optimally short-sell the asset if volatility is large enough.

In the absence of fundamental news, risk feedback is motivated by the observation that bad periods (negative returns) also tend to be more volatile. Risk feedback trading then amplifies net selling pressure and increases intraday returns persistence. Evidence to that effect has been found for the U.S. Treasury bond market by Cohen and Shin (2003). These authors report the presence of positive feedback in tick-by-tick trading on February 3, 2000, a particularly stressful day in the U.S. Treasury market: price declines (rises) elicit sales (purchases) at short horizons. Importantly, they also find positive feedback tends to be stronger when the market is under stress. To the extent that volatile market conditions tend to coincide with negative performance, the sales pressure on price will be growing in last period's volatility. The resulting conditional trading pattern can then be attributed to risk feedback.

Positive feedback trading is related to "momentum" strategies and herding behavior, while the sign asymmetry involved in risk feedback trading contributes to stabilize the market during an upswing - possibly extending the life of an asset price bubble - and to destabilize it during a downswing. Cohen and Shin (2003) argue that both short-term feedback types are more likely to arise in "pressurized" high-frequency environments where traders are subject to stop-loss constraints, such as those modeled by Morris and 
Shin (2004). Both feedback rules are more relevant at high-frequency when there is no news about fundamentals. Indeed, Hwang and Salmon (2004) report that herding behavior is independent of fundamentals also at daily frequency. ${ }^{2}$

The paper's approach follows the microstructure literature investigating the presence of temporary but persistent imbalances between asset demand and supply at the transaction level. On the empirical side, Brandt and Kavajecz (2004) report that orderflow imbalances in the U.S. Treasury market can account for over 25 percent of the daily yield variation on days without major news, while Furfine and Remolona (2005) find that the market regains its composure quickly after experiencing discontinuous price changes. ${ }^{3}$

Feedback trading models with temporary orderflow disequilibrium start with Beja and Goldman (1980). These authors employ a linear pricing rule aggregating the demands of positive feedback traders (chartists, or directional traders) and information traders (fundamentalists, or value investors). The latter trade on subjective assessments of price in relation to value and their expectation formation matters for equilibrium behavior. A key finding then is that the equilibrium price can become unstable if the proportion of positive feedback traders is sufficiently large. More recently, Day and Huang (1990) introduce a market maker and find that price behavior can be chaotic if the price impact coefficient becomes too large. Using a nonlinear pricing rule, Chiarella (1992) shows that the price level reverts to a limit cycle following a shock away from equilibrium, and dynamic instability becomes more likely as feedback traders' horizons become shorter. ${ }^{4}$

\footnotetext{
${ }^{2}$ The asymmetry inherent in risk feedback is consistent with experimental evidence suggesting that economic agents are asymmetrically loss averse (Duxbury and Summers (2004)) and exhibit both herding and contrarian behavior in simulated trading conditions (Cipriani and Guarino (2005) and Drehmann et al. (2005)).

${ }^{3}$ On the price impact of order imbalances in other markets see Andersen et al. (2004), Chakravarty (2001) and Evans and Lyons (2002).

${ }^{4}$ Farmer and Joshi (2002) and Wieland and Westerhoff (2005) extend the Day and Huang framework with stochastic information and dynamic noise. Hommes (2006) and LeBaron (2006) survey agent-based models of feedback trading. For behavioral explana-
} 
Liquidity is defined as market depth, which is inversely related to the price impact of trades (Kyle (1985)). High-frequency evidence suggests that market liquidity is time-varying, especially in stressful periods; see Dufour and Engle (2000), Farmer et al. (2005), and Goldreich et al. (2005). In view of this stylized fact, I assume that the price impact coefficient mapping net orderflow to prices follows a stationary $\mathrm{AR}(1)$ process characterized by a certain persistence and noise.

At the start of each trading period, a risk-neutral market maker receives the net orderflow and raises (lowers) the asset price if excess asset demand is positive (negative). The returns process generated by the combination of market participants' orderflow - assumed to be driven only by the most recent price fluctuation - and the market maker's linear price adjustment is shown to follow a logistic (quadratic) first-order difference equation. The logistic mapping has two fixed points, one of which is always zero while the other is generically nonzero. ${ }^{5}$ Fixed point stability then becomes a function of price impact and feedback intensity. In this paper I consider the latter to be exogenously fixed and focus attention on time-varying liquidity.

The main results are as follows. First, as price impact grows and market liquidity declines, the dynamics progressively go through the following nonoverlapping "states of the market": (i) stable, or tranquil markets, when the zero fixed point is stable and feedback trading does not affect asset returns; (ii) market stress, when the nonzero fixed point is unstable; and (iii) market turbulence, in which both fixed points are unstable. Beyond the turbulence range, the dynamics become chaotic and trading may be suspended. Hence, financial instability can be simply defined as the relative likelihood of market states (ii)-(iii), when feedback trading impacts upon asset returns, against the likelihood of tranquil state (i).

tions of herding behavior, including short-termism, see De Bondt and Thaler (1995).

${ }^{5}$ The logistic's potential for complex dynamics was realized by May (1973) and initially applied to evolutionary growth models, with positive feedback corresponding to the reproduction tendency and risk feedback to the inhibiting factor in a population. 
Second, the magnitude of the price impact thresholds separating the three states is independent of risk feedback intensity and smoothly decreasing in positive feedback intensity. Therefore, the latter is potentially destabilizing. However, given any positive feedback, volatile market-making activity - in the sense of strong price impact persistence and noise-may always result in the return dynamics entering the stress state. A key implication, then, is that although low momentum is necessary for financial stability (state (i)), it is not sufficient because states (ii)-(iii) can always arise from extreme price impact realizations.

Third, the return dynamics are reversible: stochastic price impact may, in principle, cross a threshold from either direction and re-enter the relevant market state. Episodes of market stress and turbulence can thus be said to be intermittent, after Mandelbrot's (1974) original use of the term in fluid mechanics. ${ }^{6}$ Intermittence amounts to "[...] the presence of irregular bursts in time series of a wide variety of volatility estimators" (Cont (2001)). I also find that as the market becomes stressed and turbulent, the distributions of returns and absolute return autocorrelations display power-law features ('Pareto tails'), and these become stronger as liquidity dries up.

The paper is related to the continuous-time framework of Bouchaud and Cont (1998). These authors posit behavioral-based trading rules - excess asset demand increases in positive feedback and decreases in returns volatility and loss aversion - and show that low and stable price impact can absorb big order imbalances with very small price changes. They also analyze the likelihood of a market crash as a function of the strength of feedback trading and liquidity conditions. I complement their approach by explicitly modeling time-varying price impact on a discrete time-scale, and by studying market dynamics in the absence of fundamental information other than that con-

\footnotetext{
${ }^{6}$ The potential unpredictability of a time series in the absence of shocks is central to the endogenous economic fluctuations literature; see Boldrin and Woodford (1990). Scheinkman and LeBaron (1989) presented evidence that U.S. stock returns may display chaotic behavior.
} 
tained in prices themselves, i.e. assuming "pure feedback" akin to program trading at high-frequency.

In the remainder of the paper, Section 2 presents the feedback trading model, derives its steady states and classifies their stability; Section 3 obtains a correpondence between fixed point stability and the underlying state of the market; Section 4 illustrates the dynamic transition between states numerically, and estimates power-law exponents for returns and absolute return autocorrelations for different states; Section 6 discusses some implications of intermittence; and Section 7 concludes.

\section{The model}

\section{$2.1 \quad$ Net order flow}

Consider a single risky asset traded intraday, and denote its actual return at time $t$ by $x_{t}=x(t, \Delta t)=\log P(t+\Delta t)-\log P(t)$, where $P(t)$ is the log price level at $t$. High-frequency applications often discretize the time between actual trades to $\Delta t=5 \mathrm{~min}$. For my purposes the frequency should be high enough so that fundamentals do not enter into consideration.

Asset demand is deterministically driven by the two short-term feedback trading rules discussed in Section 1. Under positive feedback, investors buy (sell) the asset at time $t$ if they observe positive (negative) returns at $t-1$. Positive feedback generates orderflow $\omega_{t}^{+}=\gamma^{+} x_{t-1} \neq 0$, where $\gamma^{+}>0$ is a scalar mapping returns at $t-1$ to asset units demanded at $t$. The case $\gamma^{+}<0$, reflecting contrarian (buy low-sell high) strategies is excluded for analytical tractability.

Contrarian behavior is effectively captured by risk feedback trading: investors sell more (less) of the risky asset at $t$ if they observe higher (lower) squared realized returns at $t-1$. Considering $x_{t-1}^{2}$ to be a volatility proxy, short-term contrarian traders employing some market equilibrium model will respond to higher $x_{t-1}^{2}$ and the associated positive expected returns for pe- 
riod $t$ by selling the asset, as they expect excess returns to mean-revert. This is related to Campbell and Hentschel's (1992) volatility-feedback hypothesis; after a bad and volatile period, such traders amplify the down movement while after a good (but less volatile) period they mitigate the up movement, so that "no news is good news".

The orderflow component from risk feedback is $\omega_{t}^{-}=-\gamma^{-} x_{t-1}^{2}<0$, where scalar $\gamma^{-}>0$ maps squared returns at $t-1$ to asset units sold at $t$. In principle, $\gamma^{+} \neq \gamma^{-}$and the intensity of each feedback type is expected to be time-varying. The net orderflow (signed trade volume) received by the market maker at time $t$ then is

$$
\begin{aligned}
\omega_{t} & =\omega_{t}^{+}+\omega_{t}^{-} \\
& =\gamma^{+} x_{t-1}-\gamma^{-} x_{t-1}^{2}
\end{aligned}
$$

Given $\gamma^{+}$and $\gamma^{-}$, the sign of $\omega_{t}$ depends on the realized return and its square over the last trading interval. Negative return shocks at $t-1$ have a larger absolute impact on orderflow at $t$ than symmetric positive shocks. As argued above, higher orderflow following a positive shock will be dampened as risk feedback cancels some of the associated momentum. This asymmetric contribution of risk feedback to asset demand is consistent with Longstaff's (2001) continuous-time asset pricing framework and the liquidity black hole model of Morris and Shin (2004), both assuming liquidity-constrained investors facing short-term trading limits.

\subsection{Stochastic price impact}

Assuming a risk-neutral market maker, so the price change depends only on the most recent orderflow and not on accumulated inventory, Farmer and Joshi (2002) derive a linear price adjustment mechanism as an approximation

\footnotetext{
${ }^{7}$ Campbell and Hentschel (1992) use a quadratic function of a $\operatorname{GARCH}(1,1)$ and find strong evidence of volatility feedback on stock market data; see also Campbell, Lo and MacKinlay (1997).
} 
of a general price impact function. Upon receiving $\omega_{t}$ a single market maker adjusts prices from $t-1$ to $t$ using the linear pricing rule

$$
x_{t}=\lambda_{t} \omega_{t}=\lambda_{t} \gamma^{+} x_{t-1}-\lambda_{t} \gamma^{-} x_{t-1}^{2}
$$

Equation (2) is consistent with order- rather than quote-driven markets. Coefficient $\lambda_{t}>0$ measures the price impact of a unit change in net orderflow. Price impact is always positive and inversely related to market liquidity, and the sign of $x_{t}$ changes with the aggregate volume imbalance. It is positive (negative) when there is net buying (selling) pressure. Further, following a negative return at $t-1$, net selling pressure has a greater absolute effect on returns at $t$ than equal buying pressure because, given $\lambda_{t}>0$, risk feedback reinforces the negative trend.

The price impact coefficient is assumed to follow an $\mathrm{AR}(1)$ process

$$
\lambda_{t}=\bar{\lambda}+\theta \lambda_{t-1}+\eta_{t}, \quad \eta_{t} \sim \operatorname{iid}\left(0, \sigma_{\eta}\right)
$$

where the price impact innovations $\eta_{t}$ are assumed to be iid. The constant term $\bar{\lambda}>0$ is inversely related to average (intraday) market liquidity. Autoregressive representation (3) is similar to that used by Acharya and Pedersen (2005) for the time-varying cost of illiquidity. ${ }^{8}$

The dynamics of price impact are driven by $\bar{\lambda}, \theta$, and the distribution of the innovation terms $\eta$. The properties of $\left\{\lambda_{t}\right\}$ are straightforward: it is covariance-stationary iff $|\theta|<1$ and nonstationary otherwise; its unconditional mean and variance are $\bar{\lambda} / 1-\theta$ and $\sigma_{\eta}^{2} / 1-\theta^{2}$, respectively; its conditional mean and variance are $\bar{\lambda}+\theta \lambda_{t-1}$ and $\sigma_{\eta}^{2}$; and its persistence at lag $k$ equals the relevant autocorrelation coefficient, $\rho(k)=\theta^{k}$.

\footnotetext{
${ }^{8}$ Esser and Mönch (2002) and Frey (2000) also model illiquidity as a mean-reverting state variable in continuous time. However, Bouchaud et al. (2004) and Upper and Werner (2002, 2007) find that the process of high-frequency price discovery displays breaks and is likely to be much more complex.
} 


\subsection{Fixed point existence and stability}

Combining equations (1), (2) and (3) yields

$$
x_{t}=h\left(x_{t-1}\right)=\lambda_{t} x_{t-1} \gamma^{+}\left[1-\frac{\gamma^{-}}{\gamma^{+}} x_{t-1}\right]
$$

Equation (4) is a quadratic (logistic) first-order difference equation describing the nonlinear relationship between returns in adjacent time intervals. In principle, the resulting dynamics are independent of the time scale $\Delta t$ used to discretize returns.

The implied covariance between successive return observations then is

$$
E\left(x_{t} x_{t-1}\right)=\gamma^{+} E\left(\lambda_{t} x_{t-1}^{2}\right)-\gamma^{-} E\left(\lambda_{t} x_{t-1}^{3}\right)
$$

Equation (5) clearly suggests that skewness matters for returns persistence; ceteris paribus, short-term persistence grows in the asymmetry captured by risk feedback trading intensity $\gamma^{-}$. Section 4.3 discusses the implications of this property for high-frequency return autocorrelations.

The fixed points of logistic map $h$ are defined as $x \equiv h\left(x_{t-1}\right)=x_{t}$. They are the equilibrium steady states of the underlying one-dimensional dynamical system; thus if asset returns equal $x$ they will remain there unless perturbed. Specifically, the two fixed points are

$$
x_{t}^{(1)}=0 \quad, x_{t}^{(2)}=\frac{1}{\gamma^{-}}\left(\gamma^{+}-\frac{1}{\lambda_{t}}\right) \neq 0
$$

Note that $x_{t}^{(1)}$ is always zero, hence I omit its time subscript, while $x_{t}^{(2)}$ is nonzero unless $\lambda_{t}=1 / \gamma^{+}{ }^{9}$ For given positive $\gamma^{+}$and $\gamma^{-}$, fixed point $x_{t}^{(2)}$ is positive when $\lambda_{t}>1 / \gamma^{+}$and negative if $\lambda_{t}<1 / \gamma^{+}$. In the first case, $x_{t}^{(2)}>0$ increases in positive feedback intensity and price impact and decreases in risk feedback intensity. In the second case $\left(x_{t}^{(2)}<0\right)$, the nonzero fixed point is absolutely decreasing in $\gamma^{+}, \gamma^{-}$and in price impact.

\footnotetext{
${ }^{9}$ The two fixed points coincide when $\lambda_{t}=1 / \gamma^{+}$. If price impact is continuously distributed then $\lambda_{t}=1 / \gamma^{+}$has zero measure, so $x_{t}^{(2)}$ is generically nonzero.
} 
The evolution of asset returns turns on the two fixed points' relative stability. A fixed point is stable (unstable) if the absolute value of the slope of (4) at that fixed point is smaller (greater) than one. The slope of $h$ with respect to $x$ is $h^{\prime}(x)=\lambda_{t} \gamma^{+}\left(1-\frac{2 \gamma^{-}}{\gamma^{+}} x\right)$. The absolute value of $h^{\prime}(\cdot)$ at $x^{(1)}$ and $x_{t}^{(2)}$ then is

$$
\begin{aligned}
& \left|h^{\prime}\left(x^{(1)}\right)\right|=\left|\lambda_{t} \gamma^{+}\right| \\
& \left|h^{\prime}\left(x_{t}^{(2)}\right)\right|=\left|2-\lambda_{t} \gamma^{+}\right|
\end{aligned}
$$

At most one fixed point can be stable at any time. Equations (7) then imply, first, that if $0<\lambda_{t}<1 / \gamma^{+}$then $x^{(1)}=0$ is stable, while $x_{t}^{(2)}<0$ is unstable. Second, if $1 / \gamma^{+}<\lambda_{t}<3 / \gamma^{+}$then $x_{t}^{(2)}>0$ is stable and $x^{(1)}=0$ is unstable. In that case, the magnitude of the stable positive fixed point grows with price impact, as $\frac{\partial x_{t}^{(2)}}{\partial \lambda_{t}}=\frac{1}{\gamma^{-} \lambda_{t}^{2}}>0$, and its sensitivity to $\lambda_{t}$ declines with risk feedback intensity $\gamma^{-}$. Third, if $\lambda_{t}>3 / \gamma^{+}$then $h^{\prime}(\cdot)$ always exceeds one. Both fixed points are then unstable and the dynamics become turbulent. Finally, if $\lambda_{t}>4 / \gamma^{+}$, the logistic map can be shown to display sensitivity to initial conditions, there are periodic points of all orders and the dynamics become chaotic.

\section{Intermittent financial (in)stability}

\subsection{Correspondence with market conditions}

The above fixed point classification indicates that asset returs in each trading interval lie in one of three possible dynamic states, depending on the strength of positive feedback $\gamma^{+}$and the determinants of price impact $\bar{\lambda}, \theta$ and $\sigma_{\eta}$. I introduce the following correspondence between fixed point stability and the "state of the market" at each point in time:

(i) Tranquil markets, corresponding to $0<\lambda_{t} \leq 1 / \gamma^{+}$. For such values, the nonzero fixed point is always negative and unstable. Consequently, the 
presence of feedback trading does not displace asset returns from zero, their equilibrium level in the absence of fundamental news.

(ii) Market stress, corresponding to $1 / \gamma^{+}<\lambda_{t} \leq 3 / \gamma^{+}$. The nonzero fixed point is now positive and stable, hence feedback trading impacts upon asset returns.

(iii) Market turbulence, where feedback trading generates unstable return dynamics $\left(3 / \gamma^{+}<\lambda_{t}<4 / \gamma^{+}\right)$.

The price impact threshold separating tranquil markets from market stress is $1 / \gamma^{+}$, while that between market stress and turbulence is $3 / \gamma^{+}$. Note that each threshold is monotonically decreasing in the intensity of positive feedback but independent of risk feedback. Stronger momentum thus makes financial instability more likely, other things equal.

For price impact values beyond $\lambda_{t}=4 / \gamma^{+}$, the logistic map generates deterministic chaos; see Devaney (1989) and Holmgren (1997). Returns diverge and the corresponding state of the market has measure zero.

\subsection{Simulation design}

In this paper I restrict $\gamma^{+}$and $\gamma^{-}$to 1 for illustration purposes; timevarying feedback intensities are discussed in Section 7. The subsequent simulations investigate the transition between states (i)-(iii) for Gaussian price impact innovations $\left\{\eta_{t}\right\} .{ }^{10}$ The returns time series $\left\{x_{t}\right\}$ is initialized at $x_{0}=\gamma^{+} / 2 \gamma^{-}=0.5$, the logistic's unique critical point. ${ }^{11}$ In turn, the price impact process is initialized at its unconditional mean: $\lambda_{1}=\bar{\lambda} / 1-\theta$ where $\bar{\lambda}=0.5$. Feeding the starting values $x_{0}$ and $\lambda_{0}$ to logistic map (4) yields $x_{1}$, the return in the next trading interval. The price impact coefficient for $t=1, \lambda_{1}$ is then computed from equation (3), the values of $x_{1}$ and $\lambda_{1}$ are fed

\footnotetext{
${ }^{10}$ Using the uniform and other non-Gaussian shock pdf's did not affect the essence of the results; these are available upon request.

${ }^{11}$ The choice of $x_{0}$ is justified by Fatou's Theorem: if the trajectories of a quadratic polynomial have an attracting periodic point, then its critical point(s) are in the stable set of one of the points in each trajectory.
} 
to equation (4) to determine $x_{2}$, etc. In this way, positive and risk feedback trading generate $t=1, \ldots, T$ observations for $\left\{x_{t}\right\}$, each characterized by a different price impact realization $\left\{\lambda_{t}\right\}$.

I present $t=1, \ldots, T=500$ price impact and return realizations for states (i), (ii) and (iii). The choice of $T$ reflects high-frequency trading in the U.S. Treasury market. Daily trading in U.S. Treasuries takes place between 7:00am and 5:00pm. Assuming, without loss of generality, that each minute in the 8 -hour period contains a single trade yields 480 trading intervals. ${ }^{12}$ The simulated asset returns can thus be viewed as snapshots of a trading day in a particular state of the market.

In order to assess the characteristics of the pdf's, the above 1-day process is run $n=1, \ldots, N=1,000$ times, yielding over 3 years of simulated highfrequency data. For each state, I report the simulated pdf's first four moments averaged over all $N$ 1-day paths. Following standard practice in nonlinear dynamic simulations, the first 200 iterated returns of each path $\left(\left\{x_{t}\right\}_{t=1}^{200}\right)$ are discarded to ensure convergence has occured. The simulated moments are then computed from the remaining $\left(\left\{x_{t=201}^{T=500}\right\}_{n=1}^{N}\right)$ iterations.

\section{Numerical simulations}

\subsection{Tranquil markets: $0<\lambda_{t} \gamma^{+} \leq 1$}

When markets are tranquil $\left(0<\lambda_{t} \leq 1\right)$ feedback trading does not affect price dynamics. To illustrate, I set the persistence of price impact to $\theta=0.2$, and assume that price impact innovations are iid distributed $\eta_{t} \sim N(0,0.05)$. Price impact is initialized at its unconditional mean, $\lambda_{1}=\bar{\lambda} / 1-\theta=0.625$. Fig. 1 below shows the simulated $\left\{\lambda_{t}\right\}$ and $\left\{x_{t}\right\}$ series

\section{FIGURE 1 HERE}

\footnotetext{
${ }^{12}$ Fleming (2001) describes the microstructure of the U.S. Treasury market.
} 
All price impact realizations are less than one, so the dynamics is in the stable range of $x^{(1)}=0$.

The simulated returns' risk-adjusted mean (sample mean/standard deviation), skewness and kurtosis averaged over all $N=1,000$ distributions, i.e. $\left\{x_{t=201}^{T=500}\right\}_{n=1}^{N}$, are reported in Table 1

Table 1: Tranquil markets

Simulated return pdf's

\begin{tabular}{|ll|}
\hline$\mu / s$ & 0.000 \\
Skewness & 8.82 \\
Kurtosis & 87 \\
\hline
\end{tabular}

Risk-adjusted expected returns are zero up to 8 decimal places. The simulated returns pdf is very skewed and fat-tailed. Excess kurtosis is broadly consistent with the high-frequency evidence: for example, Cont (2001) reports values of 15.95 for S\&P 500, 74 for US\$/DM, and 60 for returns on $\mathrm{USD} / \mathrm{SF}$ exchange rate futures.

Next, I use bifurcation diagrams to assess the evolution of fixed point stability in the price impact domain. Initializing $\lambda_{1}=0.625, i=1, \ldots, 400$ price impact realizations $\left\{\lambda_{i}\right\}$ are drawn from equation (3). For each $\lambda_{i}$, an asset return trajectory is initialized at $x_{i 0}=0.5$ as above. Each trajectory then consists of $t=1, \ldots, 300$ iterations of logistic map $(4):\left(\lambda_{i}, h^{i}(0.5)_{t=1}^{300}\right)$. The resulting behavior of return trajectories in tranquil market conditions is shown in the bifurcation diagram below

\section{FIGURE 2 HERE}

The key feature of Fig. 2 is that, at each choice of $\lambda_{i}(i=1, \ldots 100)$, the feedback return trajectories $x_{i t}(t=1, \ldots, 300)$ become dense towards zero. Price impact ranges from 0.45 to around 0.75 , hence $h$ is firmly in the stable range of $x^{(1)}=0\left(x_{t}^{(2)} \neq 0\right)$. Note that some simulated trajectories correspond 
to positive returns. However, they are unstable because feedback tradingcontinued iteration of $\left\{x_{i t}\right\}$ given $i$-attracts them back to zero. Also note that as price impact increases (liquidity declines), the unstable trajectories slope upwards and the dynamics edge towards the stress threshold.

\subsection{Market stress: $1<\lambda_{t} \gamma^{+} \leq 3$}

In the range $1<\lambda_{t} \leq 3$, the zero fixed point $x^{(1)}$ becomes unstable (repelling) and $x_{t}^{(2)}>0$ is stable (attracting). Asset returns generated by feedback trading then induce market stress: state (ii) in Section 3.1. Clearly, in order for some price impact realizations to break into the stress range, $\left\{\lambda_{t}\right\}$ has to become more persistent and/or noisy. To illustrate such dynamics, I increase the $\operatorname{AR}(1)$ coefficient to $\theta=0.5$ and double the standard deviation of liquidity shocks, so that $\eta_{t} \sim N(0,0.10)$. The price impact coefficient is now initialized at $\lambda_{1}=\bar{\lambda} / 1-\theta=1$. The simulated $\left\{\lambda_{t}\right\}$ and $\left\{x_{t}\right\}$ series are shown in Fig. 3

\section{FIGURE 3 HERE}

The market stress threshold is indicated with a horizontal line at $\lambda=1$ in the bottom panel. Price impact is less than the threshold 45.2 percent of time (300 trading periods averaged over 1,000 1-day paths), and above it the

remaining 54.8 percent. In the top panel, positive fixed point $x_{t}^{(2)}$ attracts neighboring points towards it and away from $x^{(1)}=0$. Asset returns are still close to zero (note the $10^{-8}$ scale on the vertical axis) but much more volatile than in state (i).

The risk-adjusted mean, skewness and kurtosis averaged over $\left\{x_{t=201}^{T=500}\right\}_{n=1}^{N}$ simulated return distributions are reported in Table 2 


\section{Table 2: Market stress}

Simulated return pdf's
\begin{tabular}{|ll|}
\hline$\mu / s$ & 0.0011 \\
Skewness & 1.52 \\
Kurtosis & 5.21 \\
\hline
\end{tabular}

Risk-adjusted expected returns are now positive, reflecting the fact that $x_{t}^{(2)}>0$ when $\lambda_{t} \in(1,3]$. There is much less right-skewness and leptokurtosis than in the tranquil state.

Beyond $\lambda=1, x_{t}^{(2)}$ switches from being unstable to stable. This discontinuous dynamic transition is shown in the bifurcation diagram below

\section{FIGURE 4 HERE}

The price impact coefficient now ranges from 0.75 to 1.30 . As in tranquil state (i), the return trajectories become more dense towards zero at each $\lambda_{i}$ realization. Unlike state (i), however, as $\left\{\lambda_{i}\right\}$ exceeds 1 the return trajectories slope upwards because steady-state returns have turned positive.

\subsection{Market turbulence: $3<\lambda_{t} \gamma^{+}<4$}

Asset returns enter state (iii), market turbulence, if both fixed points become unstable, which occurs when $\left|h^{\prime}(\cdot)\right|>1$. In turn, that requires price impact to be in the range $\lambda_{t}>3$. To illustrate, I maintain $\bar{\lambda}=0.5$ and $\eta_{t} \sim$ $N(0,0.10)$ but raise the $\operatorname{AR}(1)$ coefficient to $\theta=0.85$, so $\lambda_{1}=\bar{\lambda} / 1-\theta=3.33$. The simulated $\left\{\lambda_{t}\right\}$ and $\left\{x_{t}\right\}$ series are shown in Fig. 5

\section{FIGURE 5 HERE}

Only 0.4 percent of price impact realizations now falls in the tranquil state $0<\lambda_{t} \leq 1$ (bottom panel). 6.8 percent is in the stress state $1<\lambda_{t} \leq 3$, and the remaining 92.8 percent is in the turbulent range $3<\lambda_{t}<4$. There 
are no outcomes in the chaotic range $\lambda_{t} \geq 4$, and there is very pronounced volatility clustering (top panel).

Table 3 reports the risk-adjusted mean, skewness and kurtosis averaged over all $\left\{x_{t=201}^{T=500}\right\}_{n=1}^{N}$ return distributions

\section{Table 3: Market Turbulence}

Simulated return pdf's
\begin{tabular}{|ll|}
\hline$\mu / s$ & 0.0064 \\
Skewness & -0.258 \\
Kurtosis & 1.837 \\
\hline
\end{tabular}

Risk-adjusted returns are now very high; moreover, the simulated $x_{t}$ distributions have become left-skewed and there is negative excess kurtosis. Left-skewness is particularly interesting because it relates to short-horizon returns persistence. From equation (5) recall that, given $\gamma^{-}$, the first-order (adjacent ticks) autocorrelation decreases in the skewness of returns. Therefore, the switch of skewness from positive to negative along the transition from tranquil markets to turbulence (via market stress) suggests that returns persistence progressively increases as market liquidity "dries up". This property appears consistent with Cohen and Shin's (2003) evidence for the U.S. Treasury market.

The bifurcation diagram for state (iii) is in Fig. 6

\section{FIGURE 6 HERE}

Note that the dynamics begin to change very rapidly beyond the turbulence threshold. In the range $3<\lambda_{t} \leq 3.45$ there are period-doubling bifurcations. From $\lambda \simeq 3.33$, the return trajectories display a period-doubling bifurcation "cascade" familiar from chaotic dynamics. Specifically, every period-2 attracting orbit divides into an attracting period- 4 trajectory and a repelling period-2 trajectory. Another period-doubling bifurcation occurs 
when $\lambda_{i}$ is near 3.5: period-4 trajectories then split into period-8 and period16 trajectories, and so on. For $\lambda>3.6$ it can be shown that there are periodic points of all orders if a period-3 periodic point exists. Finally, beyond $\lambda_{i}=4$, the iterated return orbits can be shown to be period- $k$ for all $k>0$ and deterministic chaos emerges.

\section{Power-law properties of returns}

This Section investigates whether the asset returns generated by these dynamics are power-law distributed. I adopt the following nonparametric estimator of $\alpha$, the power-law distribution's exponent for an empirical distribution consisting of $\left\{x_{t=1}^{T}\right\}_{n=1}^{N=1,000}$ return vectors, where each vector corresponds to a day consisting of $T=500$ trading periods $(\text { ticks })^{13}$

$$
\widehat{\alpha}_{n}=1+T\left[\sum_{t=1}^{T} \log \left(\frac{x_{t n}}{x_{\min }^{n}}\right)\right]^{-1}
$$

where $x_{\min }^{n}$ is the minimum obervation in returns vector $n$ that could be consistent with a power-law distribution. The power-law exponent estimator in (8) is always greater than 1 , implying that all moments $m \geq \widehat{\alpha}_{n}+1$ will diverge. Note that the summation terms are well-defined in the market stress and turbulence states, where the negative fixed point is unstable, but not in the tranquil state where returns can be negative. This $\alpha$-estimator has the advantage of being less biased than regression methods, also in small samples, and is equivalent to the Hill estimator; see Hall (1982) and Newman (2005). However, it need not give the right estimate if the true dgp is not Pareto-type.

I use the same $\theta$ and $\sigma$ values for each dynamic state as in Section 4, motivated by the U.S. Treasury market's microstructure. Averaging $\widehat{\alpha}_{n}$ over $n=1, \ldots, N=1,000$ 1-day paths for each parameter combination, the mean

\footnotetext{
${ }^{13}$ The power-law exponent is $\alpha$, where the Pareto-tail probability of returns $x$ is proportional to $P_{\alpha}(x) \sim \frac{A^{\alpha}}{|x|^{1+\alpha}}$ for $x \rightarrow \pm \infty$.
} 
value of the power-law exponent is $\widehat{\alpha}=\left(\sum_{n=1}^{N} \widehat{\alpha}_{n}\right) / N$. The $\widehat{\alpha}$ values for each state are reported in Table 4

\section{Table 4: Power-law exponents of returns ${ }^{14}$}

\begin{tabular}{|ll|}
\hline Market state $(\theta, \sigma)$ & $\widehat{\alpha}$ \\
Tranquil & 1.01 \\
Stress & 1.43 \\
Turbulence & 2.54 \\
\hline
\end{tabular}

The estimates suggest that returns are power-law distributed in all 3 states. Indeed, the exponent is closest to one in the tranquil and stress states, suggesting that all the corresponding moments diverge. However, this finding should be treated with caution because the minimum return realizations $x_{\min }^{n}$ are arbitrarily close to zero in each of the $N$ paths, and particularly in state (i). This tends to lower all $\widehat{\alpha}_{n}$ estimates and their average. ${ }^{15}$ By contrast, the 2.54 exponent estimate for state (iii) is close to the lower end of the $2-5$ range reported by Bouchaud and Cont (2001), indicating that skewness, kurtosis and higher moments will likely diverge during turbulence.

I now turn to assess the persistence properties of returns. The autocorrelation coefficients of absolute return powers at lag $\tau$ are defined as $\rho(t, \tau)=\operatorname{corr}\left[\left|x_{t}\right|^{\delta},\left|x_{t-\tau}\right|^{\delta}\right]$. As there is sufficient consensus that autocorrelations decay slowest when $\delta=1$, i.e. absolute returns, I report on that case only; see Bouchaud and Cont (2001). The absolute return autocorrelograms for $\tau=1, \ldots, 100$ lags (ticks corresponding to 5 min) during market stress and turbulence are respectively shown in Figs. 7 and $8^{16}$

\section{FIGURES 7 AND 8 HERE}

\footnotetext{
${ }^{14}$ The $(\theta, \sigma)$ parameter values for each state are as before. The empirical histograms of $\widehat{\alpha}_{n}$ are available upon request.

${ }^{15}$ Another reason why $\alpha$ estimates in state (i) are unreliable is that excluding negative (tranquil) return observations reduces the effective sample size.

${ }^{16}$ For consistency with Fig. 3 above, Fig. 7 shows three autocorrelation paths. .
} 
In both cases, the decay patterns of $\rho(t, \tau)$ clearly suggest the presence of long memory. During stress (Fig. 7) this appears to be declining smoothly and is more pronounced than the corresponding squared-returns autocorrelogram in Bouchaud and Cont (2001) for the same maximum lag number. During market turbulence (Fig. 8), persistence is even stronger but unexploitable because of the rapidly alternating signs.

The negative autocorrelations present a computational problem, in that the resulting power-law exponents estimated from equation (8) are complexvalued. I circumvent this by using the absolute value of the autocorrelation coefficient at all lags in the estimation; as persistence is symmetrical, this transformation does not affect its properties. Fig. 9 below reports the empirical histograms of $\alpha$-exponents in states (ii) and (iii), respectively computed from $N=1,000$ daily return paths

\section{FIGURE 9 HERE}

The wide range of $\alpha$-exponents of absolute-return autocorrelation reflects the rapid oscillation of returns, particularly during turbulence. For example, the exponent for the particular autocorrelation pattern shown in Fig. 8 was 1.80. The first four moments of the power-law exponents included in the empirical histograms of Fig. 9 are reported below

\section{Table 5: Absolute return autocorrelations}

Power-law exponent descriptive statistics
\begin{tabular}{|lll|}
\hline Market state & Stress & Turbulence \\
mean & 3.17 & 3.04 \\
s.d. & 2.39 & 2.88 \\
skewness & 2.26 & 3.44 \\
kurtosis & 10.85 & 18.14 \\
\hline
\end{tabular}

Table 5 indicates that the mean $\alpha$-exponent of absolute return autocorrelations is about 3 in both states, indicating that only kurtosis is undefined. 
Both distributions are significantly right-skewed and fat-tailed, and more so for market turbulence. The tentative conclusion from the simulation evidence is that the persistence of absolute returns displays power-law features.

\section{Discussion}

The numerical simulations in Section 4 suggest a positive relationship between the values of $\theta$ and $\sigma$ and the likelihood of a dynamic transition from tranquil to turbulent markets. Smaller price impact (greater liquidity) improves the zero fixed point's stability, while bigger price impact tends to destabilize it, all else equal. In other words, stable market-making is critical for maintaining financial stability. Given any intensity of feedback trading, liquidity should be sufficiently high and stable at each point in time - in the sense of weak persistence and small variance of price impact - to guarantee the tranquil market state.

However, the transition between two dynamic states can go in both directions. Turbulence is thus reversible, or intermittent in the sense of Mandelbrot (1974), related also to Giardina and Bouchaud (2003) and Heagy et al. (1994). To quote Shin (2004, p.150), "occasionally, financial markets experience episodes of turbulence of such an extreme kind that they appear to stop functioning". Accordingly, one interpretation of the high-frequency evidence offered by Morris and Shin (2004) is that active markets can undergo mini-liquidity gaps several times in a day. Intermittent turbulence is also consistent with Plantin et al. (2004), who find less liquid asset markets are more vulnerable to episodes of turbulence. In the same vein, Danielsson and Payne (2001) find intermittent "liquidity gaps" in electronic limit order book-based FX trading.

The framework also serves to illustrate the asymmetric effects of net orderflow on prices. On one hand, excess buying pressure through positive feedback is always mitigated by risk feedback. On the other hand, risk feed- 
back acts to amplify excess selling pressure. This asymmetry is in line with evidence of relatively long periods of asset price rises-Alan Greenspan's irrational exuberance - followed by very steep price declines; Shiller (2005) considers such patterns to be asset price bubbles. The simplifying assumption that positive and risk feedback operate only on the last period's returns seems consistent with accounts of short-termism in financial markets. Trichet (2005) outlines alternative rationales for market participants' preoccupation with short-term results; these range from marking-to-market and benchmarking of performance against competitors, to the spread of index management and VaR considerations.

Finally, note that purely deterministic feedback trading cannot generate a collapsing asset price, because $x_{t}^{(2)}<0$ is unstable for all $0<\lambda_{t} \gamma^{+}<1$. Thus, the dynamics generated by logistic map (4) can only sustain zero or positive asset returns. Allowing for the possibility of falling price levels and negative returns requires introducing a noise term $\xi_{t} \sim \operatorname{iid}\left(0, \sigma_{\xi}\right)$ affecting returns in period $t$. Such noise can be thought of as a stationary pricing error measuring the quality of the market microstructure; see Hasbrouck (1993). A noisy version of equation (4) would be

$$
x_{t+1}=\lambda_{t} x_{t-1} \gamma^{+}\left[1-\frac{\gamma^{-}}{\gamma^{+}} x_{t-1}\right]+\xi_{t}
$$

Simulating returns using stochastic first-order difference equation (9) is necessary for asset price bubbles to eventually burst. A straightforward numerical application of the noisy logistic map thus involves generating bubble paths for different parameterizations of $\lambda_{t}\left(\theta\right.$ and $\left.\sigma_{\eta}\right), \gamma^{+}, \gamma^{-}$and $\sigma_{\xi}$.

\section{Concluding remarks}

In this paper I investigated the potential for financial (in)stability and turbulence arising from high-frequency feedback trading in the absence of fundamental information. A logistic interaction of feedback portfolio strategies 
generated stable (tranquil), unstable (stressful) or turbulent return dynamics depending on stochastic market liquidity and fixed feedback trading intensity. The dynamics were driven by price adjustment to short-term orderflow imbalances according to the combined strength of positive feedback trading - reflecting momentum strategies - and risk feedback trading, driven by liquidity-constrained investors' volatility-dependent strategies. I obtained a well-defined correspondence between the range of stochastic price impact and the likelihood of each dynamic state. Importantly, price impact can cross the thresholds separating the dynamic states in both directions, so the occurence of market turbulence is intermittent in Mandelbrot's sense.

The numerical calibration was motivated by high-frequency trading in the U.S. Treasury market and its microstructure. Empirically, the contrarianbased (volatility feedback) interpretation of risk feedback in Section 2 may offer a useful avenue for estimating feedback intensities by fitting difference equation (2) to lower-frequency data. However, for such applications feedback trading would have to be integrated within a market-clearing model. Analytically, the dynamics was kept tractable by fixing the intensities of both trading rules and limiting feedback to the last trading interval. In that regard, two important extensions involve allowing stochastic price impact to depend on the market's realized volatility, and introducing time-varying feedback intensities in response to the fluctuating heterogeneity of market opinion. Overall, the framework serves to underline the key role of stochastic price impact in driving high-frequency market dynamics, as well as influencing the long-memory properties of returns and their persistence. 


\section{References}

[1] Abreu, D. and M. Brunnermeier 2003. Bubbles and crashes, Econometrica 71: 173-204.

[2] Acharya, V. and L. Pedersen 2005. Asset pricing with liquidity risk, Journal of Financial Economics 77: 375-410.

[3] Andersen, T., T. Bollerslev F. Diebold and C. Vega 2004. Micro effects of macro announcements: real-time price discovery in foreign exchange, American Economic Review 93: 38-62.

[4] Beja, A. and M. Goldman 1980. On the dynamic behavior of prices in disequilibrium, Journal of Finance 35: 235-248.

[5] Black, F. 1976. Studies of stock price volatility changes, in Proceedings of the 1976 Meetings of Business $\&$ Economics Section of the American Statistical Association: 177-181.

[6] Black, F. 1986. Noise, Journal of Finance 41: 519-543.

[7] Boldrin, M. and M. Woodford 1990. Equilibrium models displaying endogenous fluctuations and chaos, Journal of Monetary Economics 25: 189-222.

[8] Borio, C. 2000. Market liquidity and stress: selected issues and policy implications, BIS Quarterly Review, November: 38-51.

[9] Bouchaud, J.-P., Y. Gefen, M. Potters and M. Wyart 2004. Fluctuations and response in financial markets: the subtle nature of 'random' price changes, Quantitative Finance 4: 176-190.

[10] Bouchaud, J.-P. and R. Cont 1998. A Langevin approach to stock market fluctuations and crashes, European Physics Journal B 6: 543-550. 
[11] Brandt, M. and K. Kavajecz 2004. Price discovery in the U.S. Treasury market: The impact of orderflow and liquidity on the yield curve, Journal of Finance 59: 2623-2654.

[12] Brunnermeier, M. and L. Pedersen 2005. Predatory trading, Journal of Finance 60: 1825-1863.

[13] Campbell, J. and L. Hentschel 1992. No news is good news: An asymmetric model of changing volatility in stock returns, Journal of Financial Economics 31: 281-318.

[14] Campbell, J., S. Grossman and J. Wang 1993. Trading volume and serial correlation in stock returns, Quarterly Journal of Economics 108: 90539.

[15] Campbell, J., A. Lo and C. MacKinlay 1997. The Econometrics of Financial Markets, Princeton University Press.

[16] Chakravarty, S. 2001. Stealth-trading: Which traders' trades move stock prices? Journal of Financial Economics 61: 281-307.

[17] Chiarella, C. 1992. The dynamics of speculative behavior, Annals of Operations Research 37: 101-123.

[18] Cifuentes, R., G. Ferrucci and H.-S. Shin 2004. Liquidity risk and contagion, Bank of England Working Paper 264.

[19] Cipriani, M. and A. Guarino 2005. Herd behavior in a laboratory financial market, American Economic Review 95: 1427-1443.

[20] Cohen, B. and H.-S. Shin 2003. Positive feedback trading under stress: evidence from the US Treasury securities market, BIS Working Paper No. 122. 
[21] Cont, R. 2001. Empirical properties of asset returns: stylized facts and empirical issues, Quantitative Finance 1: 223-236.

[22] Danielsson, J. and R. Payne 2001. Measuring and explaining liquidity on an electronic limit order book: evidence from Reuters D2000-2, LSE working paper.

[23] Day, R. and W. Huang 1990. Bulls, bears and market sheep, Journal of Economic Behavior and Organization 14: 299-329.

[24] De Bondt, W. and R. Thaler 1995. Financial decision making in markets and firms: a behavioral perspective, in R. Jarrow, V. Maksimovic and W. Ziemba (eds.), Handbook of Finance, Elsevier.

[25] Devaney, R. 1989. An Introduction to Chaotic Dynamical Systems, Addison-Wesley.

[26] Drehmann, M., J. Oechssler and A. Rider 2005. Herding and contrarian behavior in financial markets: An Internet experiment, American Economic Review 95: 1403-1426.

[27] Dufour, A. and R. Engle 2000. Time and the price impact of a trade, Journal of Finance 55: 2467-2498.

[28] Duxbury, D. and B. Summers 2004. Financial risk perception: Are individuals variance averse or loss averse?, Economics Letters 84: 21-28.

[29] Esser, A. and B. Mönch 2002. Modeling feedback effects with stochastic liquidity, working paper, Goethe Universität, Frankfurt.

[30] Evans, M. and R. Lyons 2002. Orderflow and exchange rate dynamics, Journal of Political Economy 110: 170-180.

[31] Farmer, D. and S. Joshi 2002. The price dynamics of common trading strategies, Journal of Economic Behavior and Organization 49: 149171. 
[32] Farmer, J., L. Gillemot, F. Lillo, M. Szabolcs and A. Sen 2005. What really causes large price changes?, Quantitative Finance 4: 383-397.

[33] Fleming, M. 2001. Measuring Treasury market liquidity, Federal Reserve Bank of New York Staff Reports No. 133, July.

[34] French, K., G. Schwert and R. Stambaugh 1987. Expected stock returns and volatility, Journal of Financial Economics 19: 3-30.

[35] Frey, R. 2000. Market illiquidity as a source of model risk in dynamic hedging, in R. Gibson (ed.), Model Risk, RISK Publications, London.

[36] Furfine, C. and E. Remolona 2005. Price discovery in a market under stress: the U.S. Treasury market in Fall 1998, Fed. Res. Bank of Chicago WP 2005-06.

[37] Giardina, I. and J.-P. Bouchaud 2003. Bubbles, crashes and intermittency in agent-based market models, European Physical Journal B 31: 421-437.

[38] Goldreich, D., B. Hanke and P. Nath 2005. The price of future liquidity: Time-varying liquidity in the U.S. Treasury market, Review of Finance 9: $1-32$.

[39] Hall, P. 1982. On some simple estimates of an exponent of regular variation, Journal of the Royal Statistical Society B 44: 37-42.

[40] Heagy, J., N. Platt and S. Hammel 1994. Characterization of on-off intermittency, Physics Review E 49: 1140.

[41] Hasbrouck, J. 1993. Assessing the quality of a security market: a new approach to transaction-cost measurement, Review of Financial Studies 6: 191-212. 
[42] Holmgren, R. 1997. A First Course in Discrete Dynamical Systems, New York, NY: Springer.

[43] Hommes, C. 2006. Heterogeneous agent models in economics and finance, in L. Tesfatsion and K. Judd (eds.), Handbook of Computational Economics, vol. 2: Agent-Based Computational Economics, Elsevier.

[44] Hwang, S. and M. Salmon 2004. Market stress and herding, Journal of Empirical Finance 11: 585-616.

[45] Kyle, A. 1985. Continuous auctions and insider trading, Econometrica 53: $1315-1335$.

[46] LeBaron, B. 2006. Agent-based computational finance, in L. Tesfatsion and K. Judd (eds.), Handbook of Computational Economics, vol. 2: Agent-Based Computational Economics, Elsevier.

[47] Longstaff, F. 2001. Optimal portfolio choice and the valuation of illiquid securities, Review of Financial Studies 14: 407-431.

[48] Mandelbrot, B. 1974. Intermittent turbulence in self-similar cascades, Journal of Fluid Mechanics 62: 331.

[49] May, R. 1973. Stability and Complexity in Model Ecosystems, Princeton, NJ: Princeton University Press.

[50] Morris, S. and H.-S. Shin 2004. Liquidity black holes, Review of Finance 8: $1-18$.

[51] Newman, M. 2005. Power laws, Pareto distributions and Zipf's law. Contemporary Physics 46: 323-351.

[52] Pastor, L. and R. Stambaugh 2003. Liquidity risk and expected stock returns, Journal of Political Economy 111: 642-685. 
[53] Persaud, A. 2003. (ed.) Liquidity Black Holes: Understanding, Quantifying and Managing Financial Liquidity Risk, Risk Books.

[54] Plantin, G., H. Sapra and H.-S. Shin 2004. Fair value reporting standard and market volatility, in H.-S. Shin (ed.), Derivatives Accounting and Risk Management: Key Concepts and the Impact of IAS 39, Risk Books.

[55] Scheinkman, J. and B. LeBaron 1989. Nonlinear dynamics and stock returns, Journal of Business 62: 311-337.

[56] Shiller, R. 2005. Irrational Exuberance, Princeton, NJ: Princeton University Press.

[57] Shin, H.-S. 2004. (ed.) Derivatives Accounting and Risk Management: Key Concepts and the Impact of IAS 39, Risk Books.

[58] Taleb, N. 1997. Dynamic Hedging, John Wiley.

[59] Trichet, J.-C. 2005. Asset price bubbles and their implications for monetary policy and financial stability, in W. Hunter, G. Kaufman and M. Pomerleano (eds.), Asset Price Bubbles: The Implications for Monetary, Regulatory, and International Policies, MIT Press.

[60] Upper, C. and T. Werner 2002. Time variation in the tail behaviour of Bund futures returns, ECB Working Paper 199, December.

[61] Upper, C. and T. Werner 2007. The tail wags the dog: time-varying information shares in the Bund market, BIS Working Paper 224, January.

[62] Wieland, C. and F. Westerhoff 2005. Exchange rate dynamics, central bank interventions and chaos control methods, Journal of Economic Behavior \& Organization 58: 117-132. 
FIGURE 1
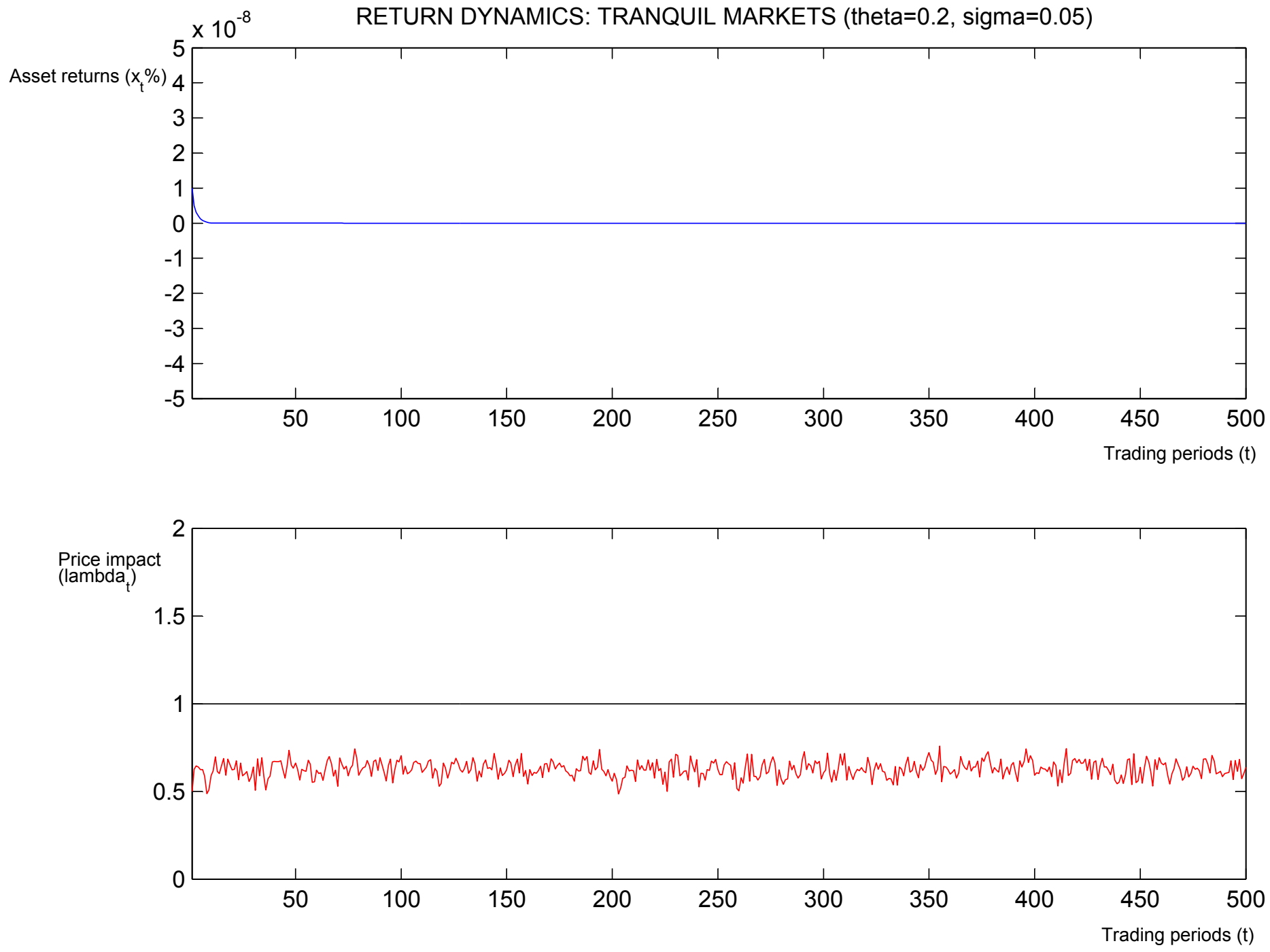
FIGURE 2

BIFURCATION DIAGRAM: TRANQUIL MARKETS (theta=0.2, sigma=0.05)

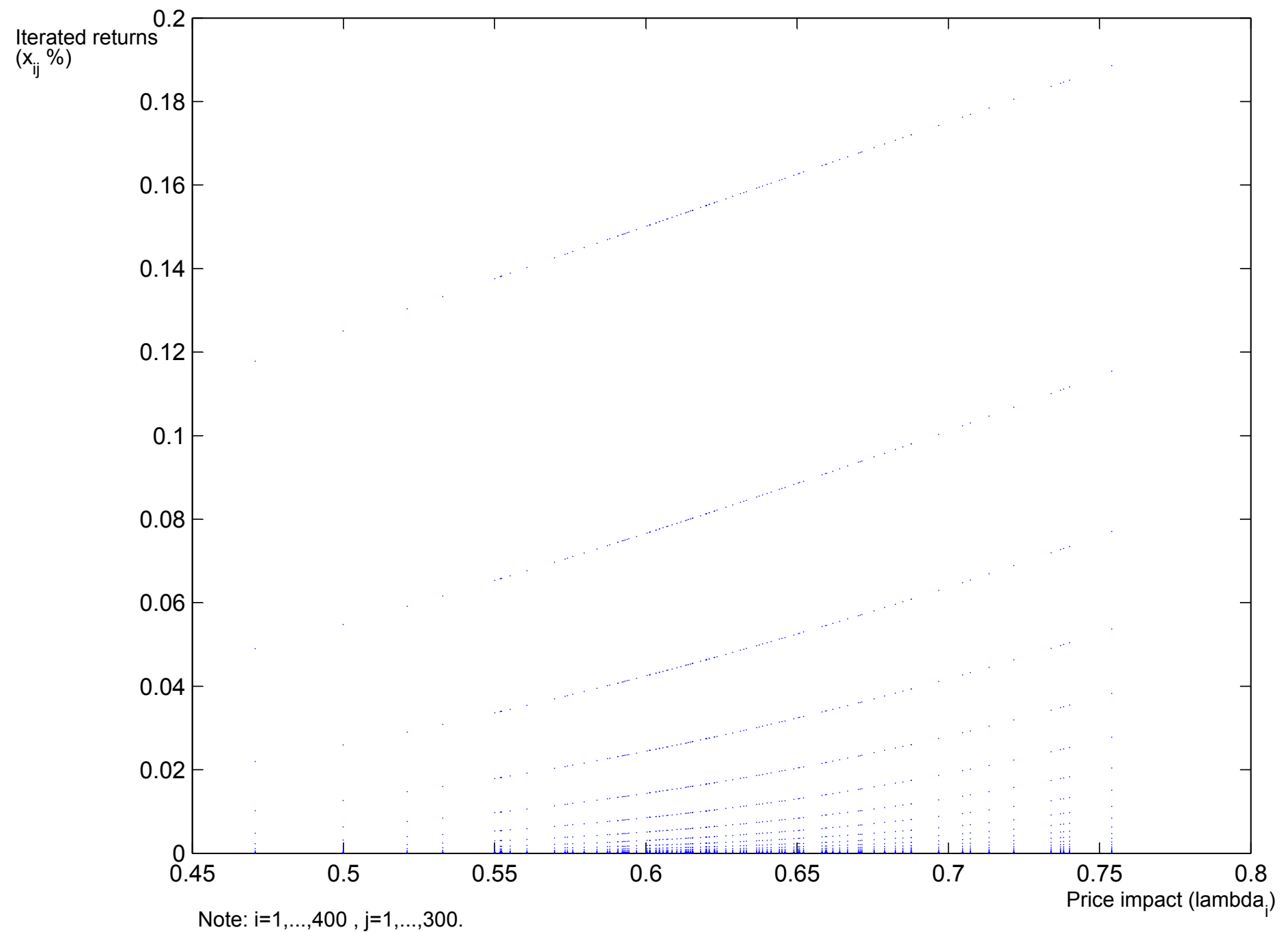



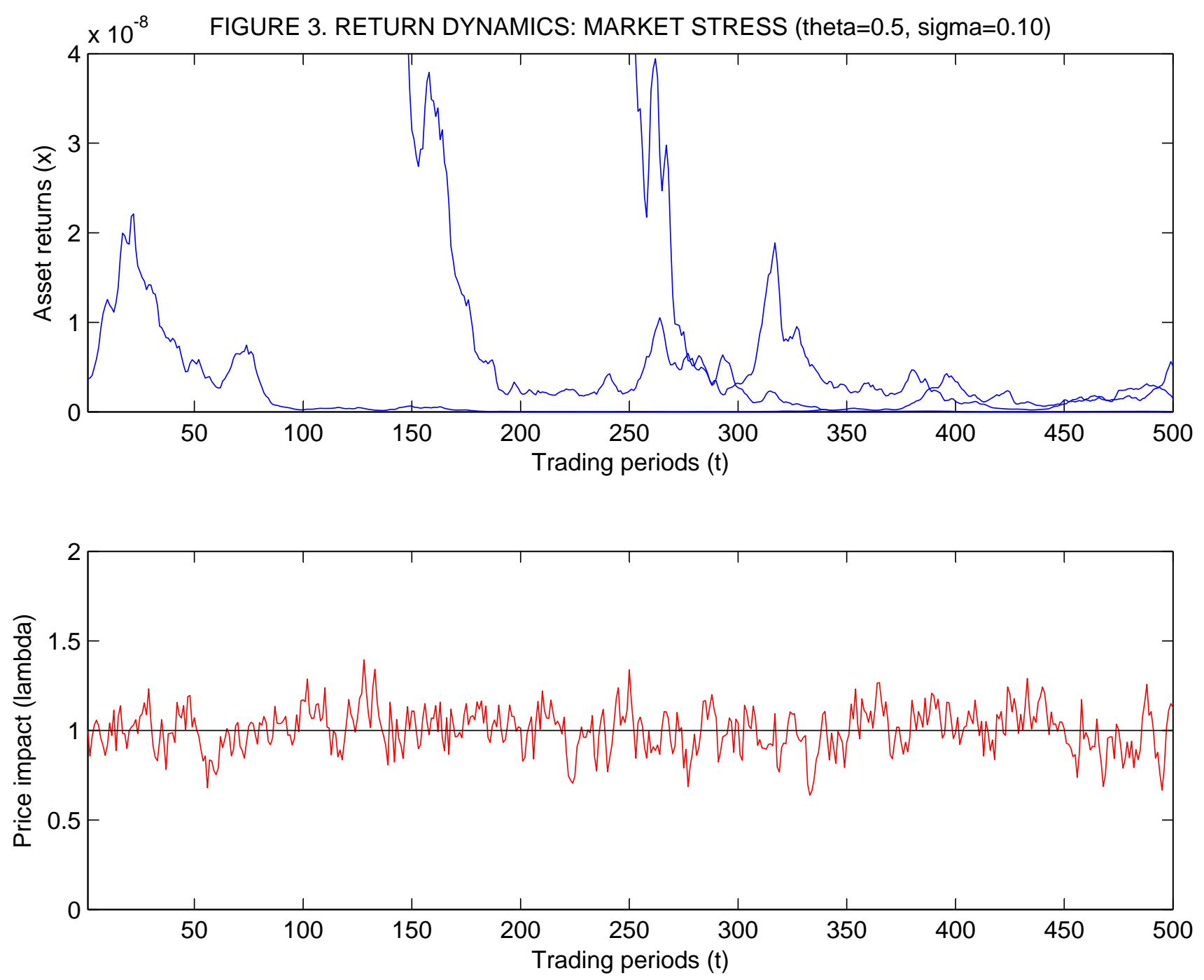
FIGURE 4

BIFURCATION DIAGRAM: MARKET STRESS (theta=0.5, sigma=0.10)

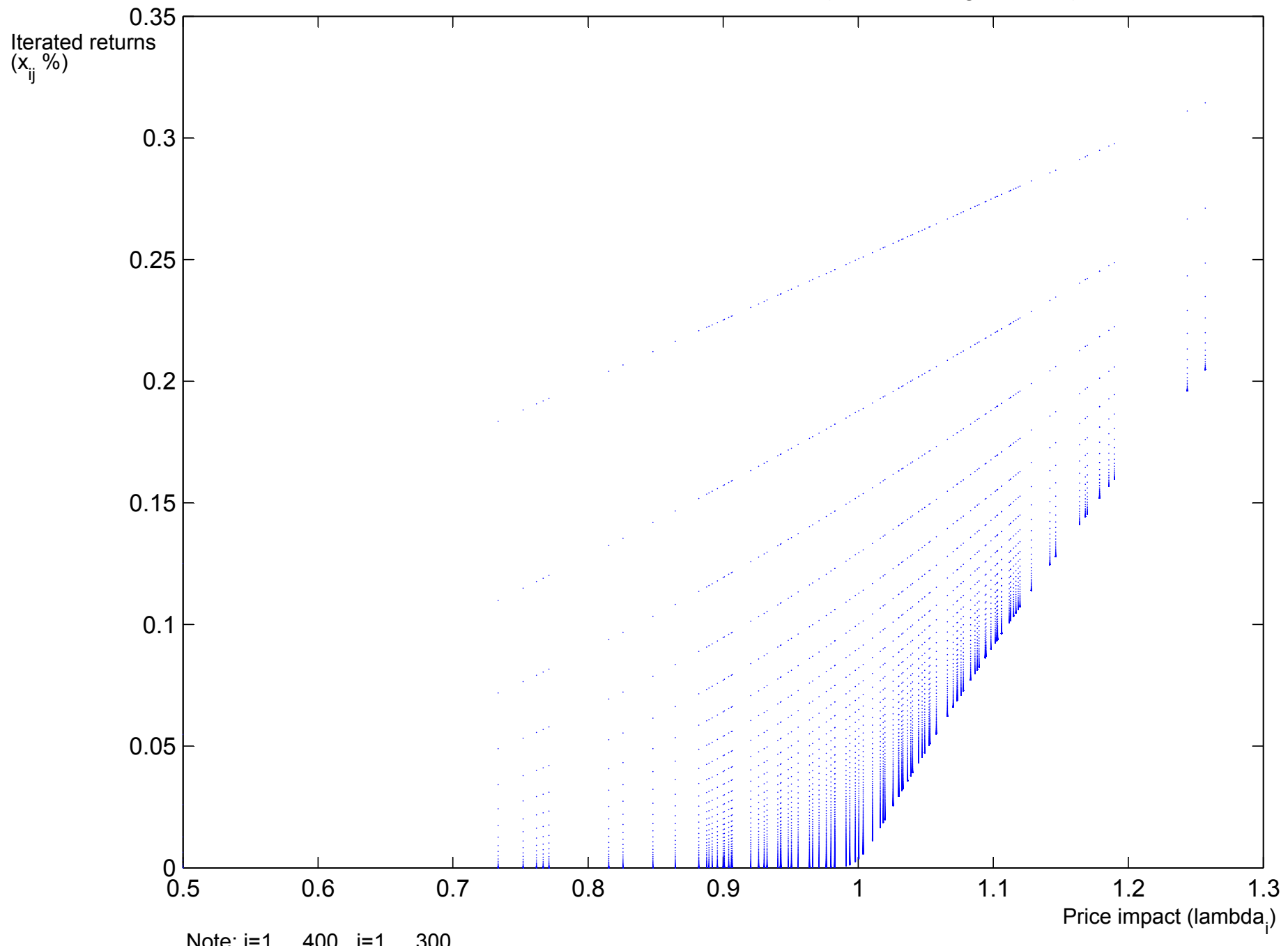


FIGURE 5

RETURN DYNAMICS: MARKET TURBULENCE (theta $=0.85$, sigma $=0.10$ )
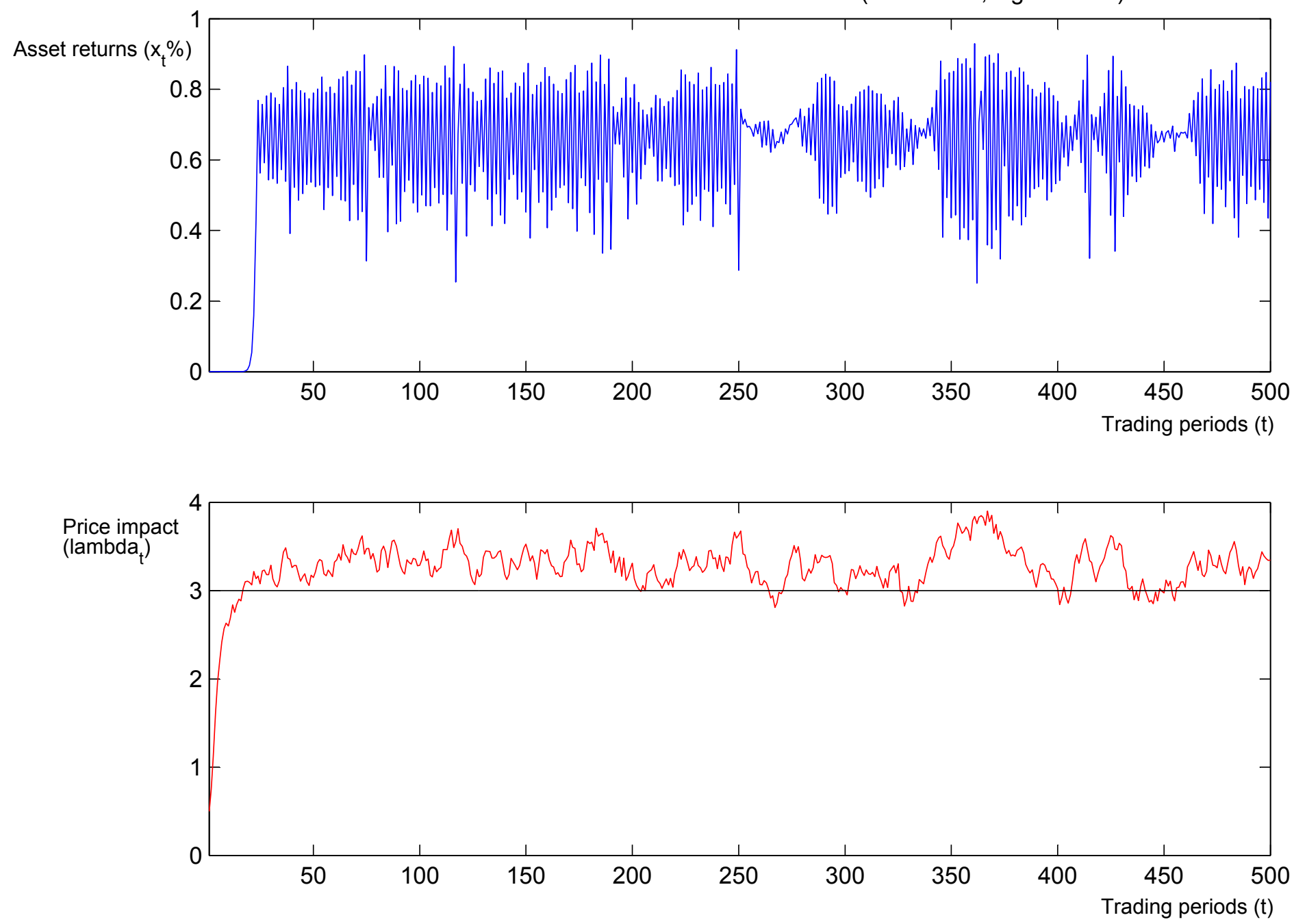
FIGURE 6

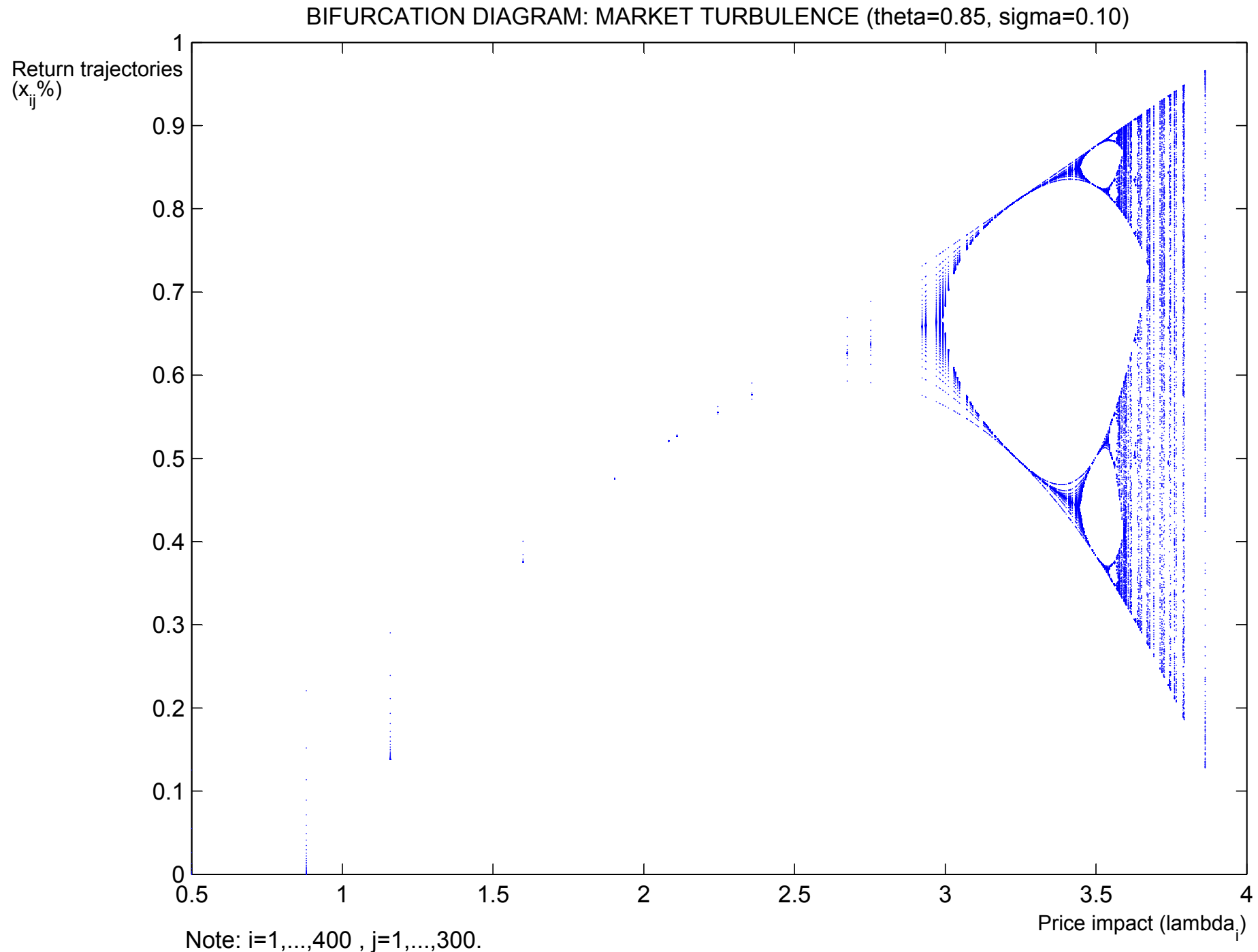


FIGURE 7. ABSOLUTE RETURN AUTOCORRELATIONS: MARKET STRESS (theta $=0.5$, sigma $=0.10$ )

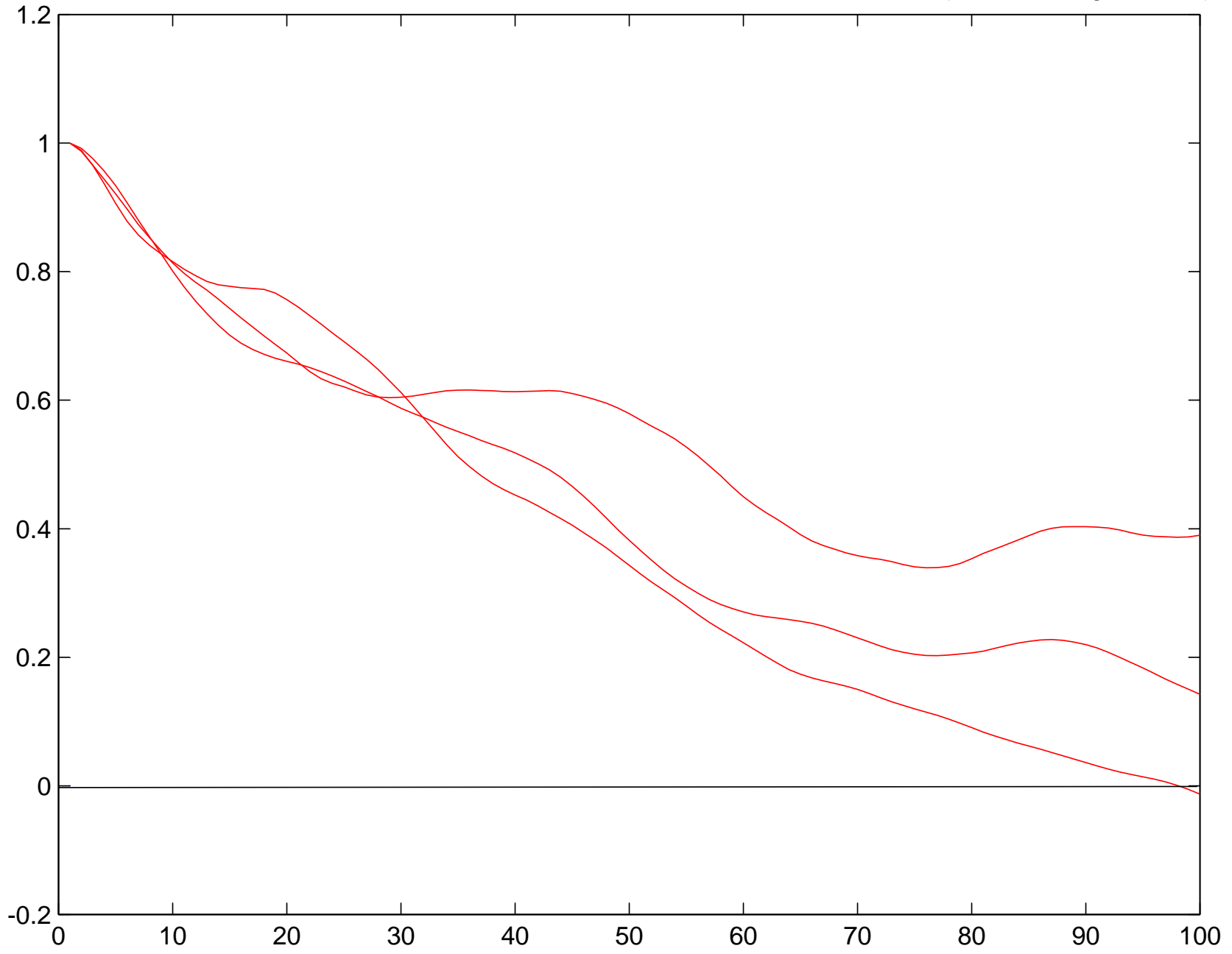




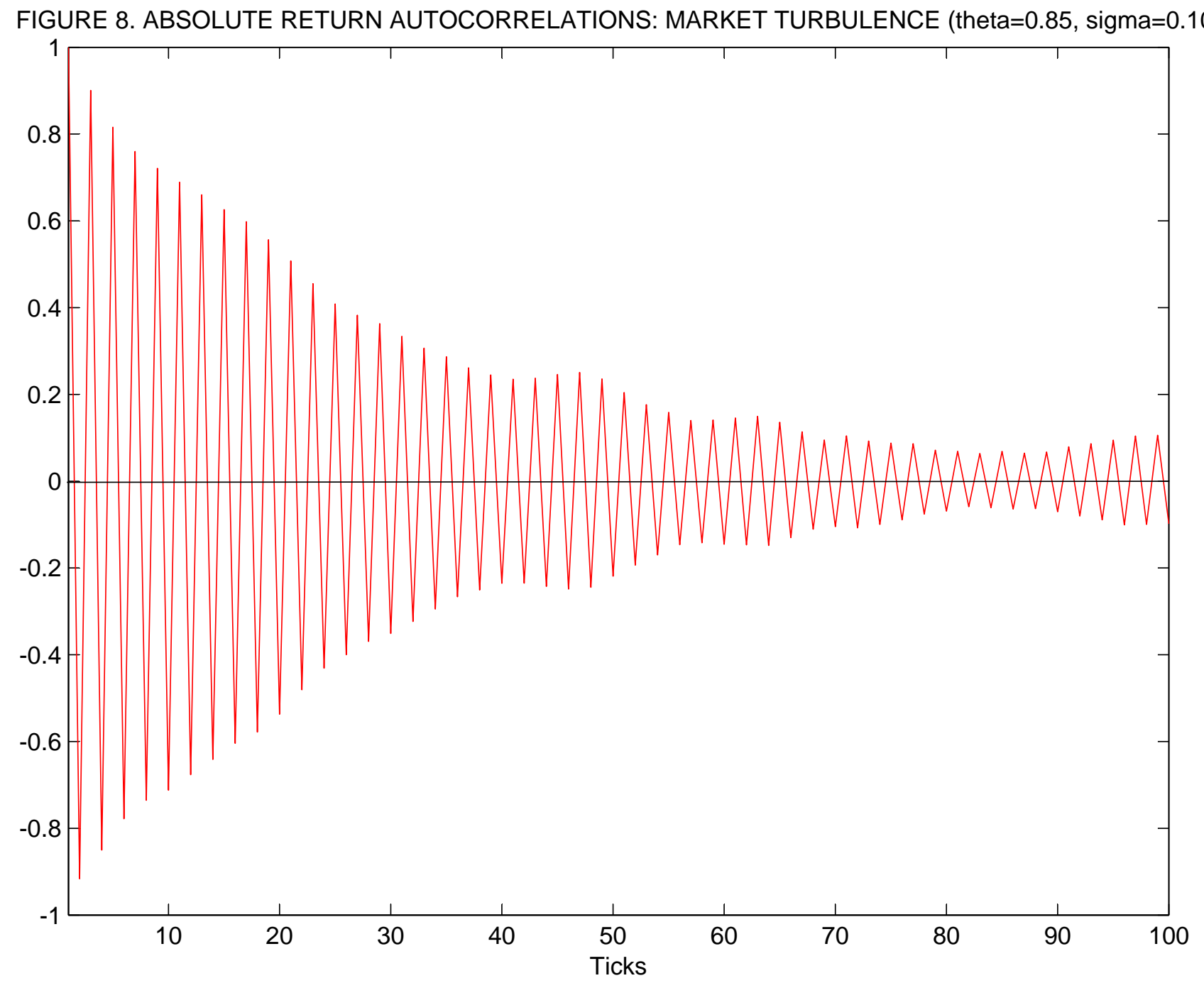


FIGURE 9. EMPIRICAL HISTOGRAMS OF ABSOLUTE RETURNS AUTOCORRELATION FUNCTION EXPONENT: STRESS
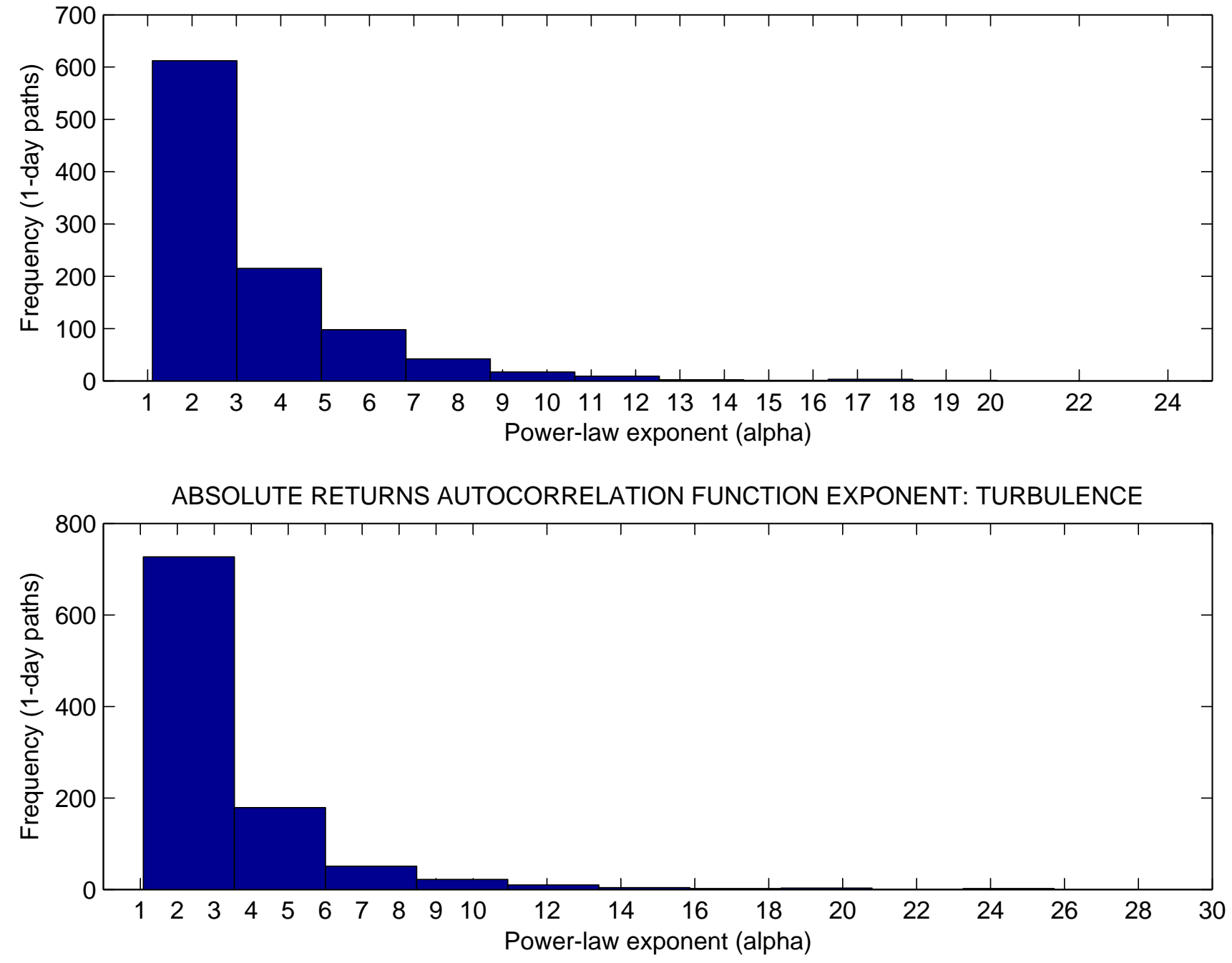